\title{
Psycho-emotional stress - A cause of coronary artery disease
}

\section{Davidraj Chellappan, Jipnomon J oseph, Mohamed M. Shabi, Gayathri Krishnamoorthy, Dhevi Ravindhran, Subashini Uthrapathy, Victor G. Rajamanickam \& Govindha P. Dubey}

\begin{abstract}
Psycho-emotional stress is one of the risk factors for metabolic syndrome and related diseases. Hence, this study has designed to the effect of psycho-emotional stress in the form of immobilization stress in rabbits. In this study, we used 12 male New Zealand White rabbits (2.5 -3 kg body weight), Six animals for hanging fixation and another six as control. Blood samples were taken before hanging ( 0 minute) and at 60, 120 minutes. Serum was separated and used for the estimation of various biochemical parameters. Hanging fixation appears to produce significant increase in malondialdehyde and lipid profile levels. The non-enzymatic antioxidants like reduced glutathione, vitamin E and ceruloplasmin were found to be decrease and the level of enzymatic antioxidant like glutathione peroxidase was increased significantly. The results reveal that the hanging fixation may develop coronary artery disease. This is the area, which should be evaluated further by carrying out chronic studies in hung stress and by histopathological studies.
\end{abstract}

Keywords: Lipid Profile, Oxidative Stress, Hung Stress, Rabbit, Lipid Peroxidation. 


\section{INTRODUCTION}

Psycho-emotional stress is acting upon a large human population in the entire country due to various metabolic symptoms. It induces strain upon both emotional and physical endurance, which has been considered to be a basic factor in the aetiology of a number of diseases e.g. cardiovascular diseases, cancer, diabetes mellitus, etc. [9].

As stress related disease like cardio vascular disease and attempt to suicide by hang increases, it is felt necessary to characterize various biological changes caused by stress. Forced immobilization caused in animals by hung them at a height produces both emotional as well as physical stress [3].

Psycho-emotional stress is one of the most potent stress models in rabbit. It strongly activates both components of the sympathoadrenal system [16] The release of catecholamines has immediate effects on both metabolism and the cardiovascular system. It also produces cell injury in several tissues. Thus, immobilization has been used as a model to induce ulceration in the stomach [4]. Damage to the heart has been demonstrated by the increase of marker enzymes in blood serum [2]. Alterations in mitochondria ultra-structure has been observed in the heart of immobilized animals [14].

Kovacs [17] have suggested that Immobilization increases Oxidative stress in rodents by stress models, including restraint. Sarov [23] have observed that immobilization along with hanging fixation seemed to be stressful enough to produce changes in glucose, lipid metabolism and MDA le-vels. But they have not recommended hanging fixa-tion for stress modeling, since the precise mechanism of observed homeostatic alterations remained to have been elucidated in further studies.

Hence, the present investigation is undertaken, to evaluate the role of antioxidants and lipid profile in rabbits, induced by immobilized hanging model for few hours and correlate the hanging stress to exert the development of coronary artery disease.

\section{MATERIALS AND METHODS}

\section{Experimental protocol}

The study was conducted in 12 male New Zealand White rabbits between 2.5 to $3 \mathrm{~kg}$ of body weight. The animals were obtained from the SASTRA animal house, Thanjavur, Tamil Nadu. They were maintained in controlled temperature $\left(23 \pm 3^{\circ} \mathrm{C}\right)$ and humidity 60-65\% with $12 \mathrm{~h}$ dark and light cycle. Rabbits had free access to sterile water and standard rabbits chow purchased from Tetragon Chemie Pvt. Ltd., Doddaballapur Bangalore. The animals had enough acclimatization for 1 week to laboratory conditions; such rabbits were used for the present investigation.

The chow was removed $6 \mathrm{~h}$ before hanging fixation. Six rabbits were fixed in retaining bag and hung with only their head, neck and legs outside the restrainer for $2 \mathrm{~h}$ as shown in Figure 1. Another six rabbits were kept as control group [24]. Blood were collected at minutes 0 , (before hanging fixation) 60 and 120 after hanging fixation from both the hung stressed and control groups. Blood samples were allowed to clot at room temperature and serum samples were separated by centrifugation at $1500 \mathrm{rpm}$ for 10 minutes. Various biochemical parameters like thiobarbituric acid reactive substances [19], lipid hydroperoxide [13], reduced glutathione (Buetlar, 1967), glutathione peroxidase [22], ceruloplasmin [21], Vitamin E [5], serum total cholesterol, high density lipoprotein (HDL), very low density lipoprotein (VLDL) low density lipoprotein (LDL) and triacylglycerol (TGL) were estimated using kits obtained from Randox, Germany.

\section{Statistical analysis}

Values mentioned in the Tables were mean \pm SD of 6 animals. One-way ANOVA was calculated using SPSS 12.0 for Windows software.

\section{RESULTS}

The level of serum TBARS was found to be increased significantly at 60 and 120 minutes $(p<0.05$, Table 1) against 0 minute of hanging fixed rabbits. Likewise lipid hydroperoxide level was also found to be increased at 60 and 120 minutes significantly $(\mathrm{p}<0.05$, Table 1) against 0 minute in hanging fixed rabbits. But in both the cases no much significant difference has been observed in the normal rabbits.

The level of non-enzymatic antioxidants like Vitamin E, reduced Glutathione and ceruloplasmin were found to be decreased significantly $(\mathrm{p}<0.05$, Table 2) in 60 and 120 minutes sample against 0 minute sample in hanging rabbits. Likewise, the level of enzymatic antioxidant like Glutathione peroxidase was found to be increased at 60 and 120 minutes 
Figure 1. Rabbit in retaining bag.

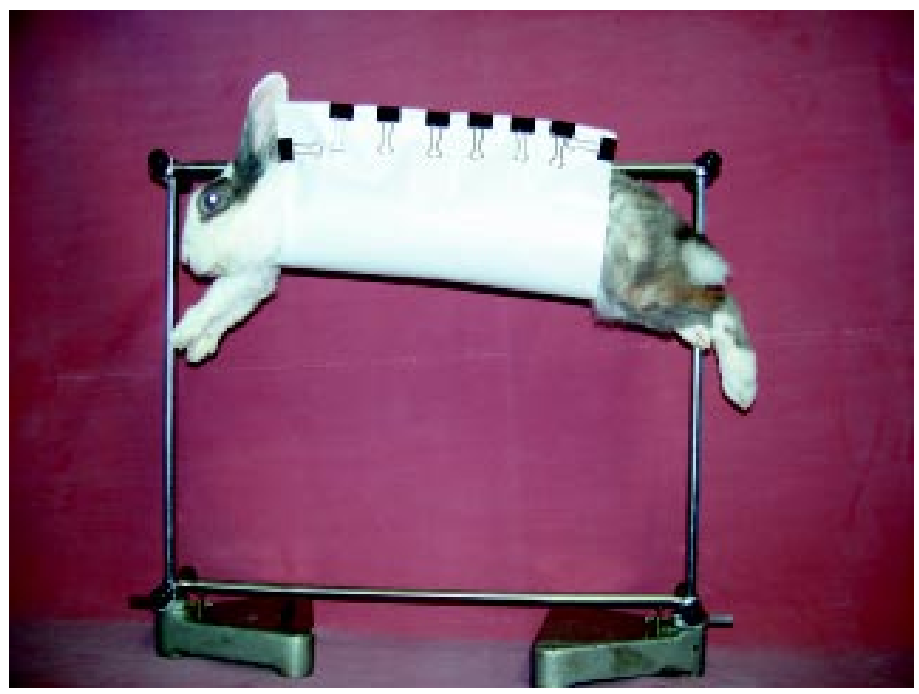

Table 1. Level of serum reactive oxygen species before and after hanging fixation of rabbits.

\begin{tabular}{|c|c|c|c|}
\hline \multirow{2}{*}{ Groups } & Time interval & $\begin{array}{c}\text { Thiobarbituric acid } \\
\text { reactive substances } \\
\text { (nm of MDA/mg of protein) }\end{array}$ & $\begin{array}{c}\text { Lipid hydroperoxide } \\
\left(\mathbf{x} \mathbf{1 0}^{-5} \mathbf{~ m M} / \mathbf{d l}\right)\end{array}$ \\
\hline \multirow{3}{*}{\begin{tabular}{c} 
Normal rabbits \\
\cline { 2 - 4 }
\end{tabular}} & 0 & $2.53 \pm 0.2^{\mathrm{a}}$ & $9.5 \pm 0.8^{\mathrm{a}}$ \\
\cline { 2 - 4 } & 60 & $2.49 \pm 0.1^{\mathrm{a}}$ & $9.3 \pm 0.6^{\mathrm{a}}$ \\
\hline \multirow{3}{*}{$\begin{array}{c}\text { Hanging fixed } \\
\text { rabbits }\end{array}$} & 120 & $2.51 \pm 0.3^{\mathrm{a}}$ & $9.4 \pm 0.7^{\mathrm{a}}$ \\
\cline { 2 - 4 } & 60 & $2.54 \pm 0.2^{\mathrm{a}}$ & $9.2 \pm 0.8^{\mathrm{a}}$ \\
\cline { 2 - 4 } & 120 & $4.32 \pm 0.1^{\mathrm{b}}$ & $18.9 \pm 0.9^{\mathrm{b}}$ \\
\hline
\end{tabular}

Values are mean \pm SD for 6 animals. Values not sharing a common superscript are differ significantly at $\mathrm{p}<0.05$.

Table 2. Level of serum enzymatic and non-enzymatic antioxidants before and after Fixation of rabbits by hung process.

\begin{tabular}{|c|c|c|c|c|c|}
\hline Groups & $\begin{array}{c}\text { Time interval } \\
\text { (minute) }\end{array}$ & $\begin{array}{l}\text { Reduced glutathione } \\
\text { ( } \mu \mathrm{M} \text { of GSH/mg } \\
\text { of protein) }\end{array}$ & $\begin{array}{c}\text { Ceruloplasmin } \\
\text { (U/dl) }\end{array}$ & $\begin{array}{c}\text { Vitamin } E \\
(\mathrm{mg} / \mathrm{dl})\end{array}$ & $\begin{array}{l}\text { Glutathione peroxidase } \\
\text { ( } \mu \mathrm{M} \text { of GSH oxidized/ } \\
\mathrm{min} / \mathrm{mg} \text { of protein) }\end{array}$ \\
\hline \multirow{3}{*}{$\begin{array}{l}\text { Normal } \\
\text { rabbits }\end{array}$} & 0 & $26.5 \pm 1.2^{\mathrm{a}}$ & $95.1 \pm 3.6^{\mathrm{b}}$ & $14.92 \pm 0.5^{\mathrm{a}}$ & $5.03 \pm 0.2^{\mathrm{a}}$ \\
\hline & 60 & $25.6 \pm 1.0^{\mathrm{a}}$ & $96.5 \pm 5.2^{\mathrm{a}}$ & $15.36 \pm 0.6^{\mathrm{a}}$ & $5.12 \pm 0.5^{\mathrm{a}}$ \\
\hline & 120 & $26.3 \pm 1.3^{\mathrm{a}}$ & $94.5 \pm 3.8^{\mathrm{a}}$ & $14.85 \pm 0.8^{\mathrm{a}}$ & $5.01 \pm 0.4^{\mathrm{a}}$ \\
\hline \multirow{3}{*}{$\begin{array}{l}\text { Hanging fixed } \\
\text { rabbits }\end{array}$} & 0 & $25.4 \pm 1.2^{\mathrm{a}}$ & $95.6 \pm 4.5^{\mathrm{a}}$ & $14.62 \pm 0.5^{\mathrm{a}}$ & $5.21 \pm 0.5^{\mathrm{a}}$ \\
\hline & 60 & $9.2 \pm 0.5^{b}$ & $42.3 \pm 3.6^{\mathrm{a}}$ & $5.89 \pm 0.6^{b}$ & $11.32 \pm 0.5^{b}$ \\
\hline & 120 & $9.8 \pm 0.6^{\mathrm{b}}$ & $45.6 \pm 2.5^{\mathrm{a}}$ & $5.32 \pm 0.5^{\mathrm{b}}$ & $11.28 \pm 0.8^{\mathrm{b}}$ \\
\hline
\end{tabular}

Values are mean \pm SD for 6 animals. Values not sharing a common superscript are differ significantly at $\mathrm{p}<0.05$. 
Table 3. Level of serum lipid profile before and after fixation of rabbits by hung Process.

\begin{tabular}{|c|c|c|c|c|c|c|}
\hline Groups & $\begin{array}{l}\text { Time interval } \\
\text { (minute) }\end{array}$ & $\begin{array}{l}\text { Cholesterol } \\
\text { (mg/dl) }\end{array}$ & $\begin{array}{c}\text { Triacylglycerol } \\
\text { (mg/dl) }\end{array}$ & $\begin{array}{c}\text { HDL } \\
(\mathrm{mg} / \mathrm{dl})\end{array}$ & $\begin{array}{c}\text { LDL } \\
(\mathrm{mg} / \mathrm{dl})\end{array}$ & $\begin{array}{l}\text { VLDL } \\
(\mathrm{mg} / \mathrm{dl})\end{array}$ \\
\hline \multirow{3}{*}{$\begin{array}{l}\text { Normal } \\
\text { rabbits }\end{array}$} & 0 & $95.6 \pm 2.5^{\mathrm{a}}$ & $85.2 \pm 2.5^{a}$ & $35.2 \pm 1.2^{\mathrm{a}}$ & $35.2 \pm 1.2^{\mathrm{a}}$ & $35.2 \pm 1.2^{\mathrm{a}}$ \\
\hline & 60 & $98.9 \pm 3.5^{\mathrm{a}}$ & $88.9 \pm 3.2^{\mathrm{a}}$ & $33.5 \pm 2.3^{a}$ & $33.5 \pm 2.3^{\mathrm{a}}$ & $33.5 \pm 2.3^{\mathrm{a}}$ \\
\hline & 120 & $96.3 \pm 2.3^{\mathrm{a}}$ & $83.5 \pm 2.3^{a}$ & $36.3 \pm 2.5^{\mathrm{a}}$ & $36.3 \pm 2.5^{\mathrm{a}}$ & $36.3 \pm 2.5^{\mathrm{a}}$ \\
\hline \multirow{3}{*}{$\begin{array}{l}\text { Hanging } \\
\text { fixed rabbits }\end{array}$} & 0 & $95.4 \pm 3.6^{\mathrm{a}}$ & $85.6 \pm 3.5^{\mathrm{a}}$ & $38.9 \pm 3.2^{\mathrm{a}}$ & $38.9 \pm 3.2^{\mathrm{a}}$ & $38.9 \pm 3.2^{\mathrm{a}}$ \\
\hline & 60 & $195.8 \pm 3.5^{b}$ & $195.6 \pm 5.6^{b}$ & $20.3 \pm 1.2^{b}$ & $20.3 \pm 1.2^{b}$ & $20.3 \pm 1.2^{b}$ \\
\hline & 120 & $200.3 \pm 4.8^{b}$ & $205.6 \pm 6.8^{b}$ & $16.9 \pm 0.9^{b}$ & $16.9 \pm 0.9^{b}$ & $16.9 \pm 0.9^{\mathrm{b}}$ \\
\hline
\end{tabular}

Values are mean \pm SD for 6 animals. Values not sharing a common superscript are differ significantly at $\mathrm{p}<0.05$.

against 0 minute in hanging rabbits. But significant difference was not observed in both enzymatic and nonenzymatic enzyme level of normal rabbit at any time like 0,60 and 120 minutes.

The level of lipid profile includes total cholesterol, triacylglycerol, VLDL and LDL level in serum sample of 60 and 120 minutes was found to be increased significantly $(\mathrm{p}<0.05$, Table 3$)$ against 0 minute sample in hanging animals. Likewise, HDL level at 60 and 120 minute was found to be decreased in the same sample against 0 minute serum. But no much significant difference in the lipid profile of normal animals was observed at any time.

\section{DISCUSSION}

Stressful conditions lead to formation of excessive free radicals, which are a major internal threat to cellular homeostasis of aerobic organisms [30]. Free radicals are formed in human body both in physiological and pathological conditions in cytosol, mitochondria, lysosomes, peroxisomes and plasma membranes [11]. These free radicals are extremely reactive and unstable chemical species, which react with proteins, lipids, carbohydrates and nucleic acids in the body [26]. Exposure of lipids in cell membrane to free radicals stimulates the process of lipid peroxidation [9]. The products of lipid peroxidation are themselves reactive species and lead to extensive membrane, organelles and cellular damage. The free radical activity and the extent of tissue damage are related quantitatively to the amount of lipid peroxide level in the blood [29]. Malondialdehyde (MDA) is one of the end products of lipid peroxidation and extent of lipid peroxidation is measured by estimating MDA levels most frequently.

The findings of this study reveal significant increase in serum MDA levels both at 60 and 120 minutes $(\mathrm{p}<0.05$, Table 1$)$ for those rabbits kept in hanging fixation for different duration. Increased MDA levels depict increased lipid peroxidation, which may be because of excessive production of free radicals after getting the hung stress. Increased level of MDA is also reported in other stress models of rabbits like starvation stress and ischaemic limb injury in rabbits [10, 27].

The increase in MDA is duration dependant. The sharp increase in MDA at 60 minutes may be because of exposure of rabbits to hung stress for the first time. Significantly increase in the levels of MDA $(p<0.05$, Table 2$)$ might be due to free radical mediated membrane damage.

Experimental in vivo and in vitro studies, as well from epidemiological studies suggest an inverse correlation between severities of oxidative stress induced diseases and levels of antioxidants (12]. Gutteridge [7] has mentioned that catalase and Glutathione peroxidase are considered biologically essential in the reduction of hydrogen peroxide. Glutathione reductase and Glutathione peroxidase are essential for maintaining constant ratio of reduced glutathione to oxidized glutathione in the cell. Significantly decreased glutathione levels $(\mathrm{p}<0.05$, Table 2$)$ in those rats kept in hung position might be due to its increased utilization in protecting -SH group containing proteins from free radicals. 
Glutathione peroxidase level was found to be increase significantly $(\mathrm{p}<0.05$, Table 2$)$. In order to protect the tissue injury caused by the free radicals produced during the occasion, liver may release much amount of glutathione peroxidase. Increased level of glutathione peroxidase is also reported in other stress models like heat stress [1].

Ceruloplasmin is an extracellular antioxidant that can scavenge superoxide radicals [18] and inhibits ferritin dependant lipid peroxidation by catalyzing the oxidative reincorporation of released iron into ferritin. Since ceruloplasmin has both ferroxidase and copper binding capacity, it could have been used more to neutralize the excess amount of free radicals and hence hung rabbits have shown a significantly decrease in ceruloplasmin $(\mathrm{p}<0.05$, Table 2$)$.

Ascorbic acid present in aqueous environment has multiple antioxidant properties including the ability to regenerate alpha tocopheryl radicals present at the surface of the membrane [15]. Because of the antioxidant property, these vitamins are utilized for the neutralization of free radicals and lipid peroxidation generated during hung process. This utilization causes the significant decreased level of Vitamins $\mathrm{E}(\mathrm{p}<0.05$, Table 2$)$ in hung rabbits.

The lipoprotein fractions are used to predict more of developing coronary artery disease than that of total cholesterol. LDL is well recognized as a risk factor and HDL as a protective factor against atherosclerosis [6]. In addition, it has been shown that $\mathrm{HDL} /$ total cholesterol ratio is one of the most powerful pointers about the risk of getting coronary artery disease [24]. HDL/total cholesterol ratio is found to decrease in this study.

Immunocyto-chemical analysis has revealed the presence of protein modified by MDA, which converts LDL, the major carrier of serum cholesterol, to an abnormal form. Receptor-mediated clearance of this altered LDL produces cholesteryl ester deposition over macrophage-derived foam cells of atheromas. These findings are the direct evidence for the existence of protein modification by a physiological product of lipid peroxidation within arterial lesions [8]. Serum samples from hypercholesterolemic rabbits and from several human subjects have been observed to contain antibodies that are found to react with peroxidized LDL, suggesting that peroxidation take place in vivo $[8,20]$.
In our present study, predominant increase of serum total cholesterol, LDL, VLDL, triacylglycerol $(p<0.05$, Table 3$)$ and noticable decrease of HDL ( $<<0.05$, Table 3$)$ have been recorded.

Swaner [28] have reported that the main cause for hypercholesterolemia during stress may be due to the continued biosynthesis, concomitant with decrease or complete absence in intestinal excretion. Segal [25] has mentioned that VLDL is reported to be increased in different hyperlipoproteinemias (Type II, III, IV and V) and may be a contributing factor in atherosclerosis.

The result supports the hypothesis that cholesterol stored in the lipid droplets of the adipose tissue cells, is released into serum and is the chief source of the hypercholesterolemia, observed during stress. The increase in triacylglycerol levels may be because of release of triacylglycerol from storage sites for the formation of glucocorticoids in response to hung stress.

The hung rabbit establishes a positive correlation among lipid profile and lipid peroxidation. It indicates that increased lipid peroxidation is associated with increased total cholesterol and LDL, the known major risk factors for atherosclerosis and other lipid peroxidation induced diseases. The observed negative correlation of MDA with HDL suggests that increased lipid peroxidation is associated with decreased HDL concentration. Decreased HDL levels may be a contributing factor in atherogenesis. In this study, increased lipid peroxidation, total cholesterol, LDL, VLDL and TGL may enable to predict the increased susceptibility of the animals to atherosclerosis as a result of the stress induced by means of hanging process. The chronic model of fixing the rabbit in the hung process should be carried out to study the effect on myocardial infarction and atherosclerosis and histopathology of heart should be carried out.

\section{CONCLUSION}

Fixation by hung means may cause the production of reactive species, release of various enzymatic antioxidants, decrease of non-enzymatic antioxidants and increase of total cholesterol and lipoproteins with decreased HDL. These results reveal that there is more ample chance for the development of coronary artery disease to those rabbits that undergo any chance of getting fixed by hung mode. The development of coronary artery disease should be evaluated by carrying out chronic study and also by histopathology. 
Acknowledgement. The authors are grateful to Prof. R. Sethuraman, Vice-Chancellor, SASTRA and his able administrative colleagues for allowing us to complete this work. We also thank to all the staffs of CARISM, SASTRA for their extraordinary support and for providing all the necessary facilities to carry out this work.

\section{REFERENCES}

1 Ando M., Katagiri K., Yamamoto S., Asanuma S., Usuda M., Kawahara I. \& Wakamatsu K. 1994. Effect of hyperthermia on glutathione peroxidase and lipid peroxidative damage in liver. Journal of Thermal Biology. 19: $177-185$.

2 Arakawa H., Kodama H., Matsuoka N. \&Yamaguchi I. 1997. Stress increases plasma enzyme activity in rats: Differential effects of adrenergic and cholinergic blockades. The Journal of Pharmacology and Experimental Therapeutics. 280: 1296-1303.

3 Axelrod J. \& Reisine T.D. 1984. Stress hormones: their regulation and interaction. Science. 224: $452-459$.

4 Buchanan D.C. \& Caul W.F. 1974. Gastric ulceration in rats induced by self-imposed immobilization or physical restraint. Physilogy and Behavior. 13: 583-588.

5 Desai J.D. 1984. Vitamin E analysis methods for animal tissues. Methods in Enzymology. vol. 105. Orlando. FL. $138-147$.

6 Gordon D.J. \& Rifkind B.M. 1989. High density lipoprotein-the clinical implications of recent studies. The New England Journal of Medicine. 321: 1311-1316.

7 Gutteridge J.M. 1995. Lipid peroxidation and antioxidants as biomarkers of tissue damage. Clinical Chemistry. 41: 18191828.

8 Haberland M., Fong D. \& Cheng L. 1988. Malondialdehyde-altered protein occurs in atheroma of Watanable heritable hyperlipidemic rabbits. Science. 241: 215-218.

9 Halliwell B. \& Gutteridge J.M. 1984. Lipid peroxidation, oxygen radicals, cell damage and antioxidant therapy. The Lancet. 1: 1396-1397.

10 Hemnani T. \& Parihar M.S. 1998. Reactive oxygen species and oxidative DNA damage. Indian Journal of Physiology and Pharmacology. 42: 440-452.

11 Izuka Y., Sakurai E. \& Hikichi N. 1992. Effects of selenium on the serum glucose and insulin levels in diabetic rats. Nippon Yakurigaku Zasshi. 100: 151-156.

12 Jiang Z.Y., Hunt J.V. \& Wolff S.P. 1992. Ferrous ion oxidation in the presence of xylenol orange for detection of lipid hydroperoxide in low-density lipoprotein. Analicatical Biochemistry. 202: 384-389.

13 Jonsson L. \& Johansson G. 1974. Cardiac muscle cell damage induced by restraint stress. Virchows Archiv - B: Cell Pathology. 17: 1-12.

14 Karthikeyan J. \& Rani P. 2003. Enzymatic and non-enzymatic antioxidants in selected Piper species. Indian Journal of Experimental Biology. 41: 135-140.

15 Kopin I.J. 1995. Definition of stress and sympathetic neuronal responses. Annals of the New York Academy of Sciences. 771: $19-30$.

16 Kovacs P., Juranek I., Stankovicova T. \& Svec P. 1996. Lipid peroxidation during Acute stress. Pharmazie. $51: 51-53$.

17 Lata H., Ahuja G.K. \& Narang A.P. 2002. Effect of starvation stress on lipid peroxidation and lipid profile in rabbits. Indian Journal of Physiology and Pharmacology. 46: 371-374.

18 Lekse J.M., Xia L., Stark J., Morrow J.D. \& May J.M. 2001. Plant catechols prevent lipid peroxidation in human plasma and erythrocytes. Molecular and Cellular Biochemistry. 226: 89-95.

19 Ohkawa H., Ohishi N. \& Yagi K. 1979. Assay of lipid peroxides in animal tissues by thiobarbituric acid reaction. Analical Biochemistry. 95: 351-358.

20 Palinski W., Rosenfeld M.E., Yla-Herttuala S., Gurter G.C., Socher S.S., Butler S.W., Parthasarathy S., Carew T.E., Steinberg D. \& Witztum J.L. 1989. Low density lipoprotein undergoes oxidative modification in vivo. Proceedings of the National Academy of Sciences. 86: 1372-1376.

21 Ravin H.A. 1961. An Improved colorimetric enzymic assay of ceruloplasmin. Journal of Laboratry Clinical Medicine. 58: 161-168.

22 Rotruck J.T., Pope A.L., Ganther H.E., Swanson A.B., Hafeman D.G. \& Hoekstra W.G. 1973. Selenium: biochemical role as a component of glutathione peroxidase. Science.179: 588-590.

23 Sarov G.M. \& Vlaykova T.I. 2005. Changes in blood glucose, triglycerides and lipid peroxidation products in rabbits after hanging fixation. Bulgarian Journal of Veterinary Medicine. 8: 157-590. 
Chellappan D., J oseph J., Shabi M.M., Krishnamoorthy G., Ravindhran D., Uthrapathy S., Rajamanickam V.G. \& Dubey G.P.

24 Segal P., Bachorik P.S., Rifkind B.M. \& Levy R.I. 1984. Lipids and dyslipoproteinemia. In: Bernard J.H., Nelson D.A., Tomar R.H. \& Washington J.A. (Eds). Clinical diagnosis and management by laboratory methods. 17th edn. Philadelphia: WB Saunders:, pp.180-203.

25 Sevanian A. \& Hochstein P. 1985. Mechanisms and consequences of lipid peroxidation in biological systems. Annual Review of Nutrition. 5: 365-390.

26 Singhal S., Agarwal D.K. \& Srivastava V. 1997. Effect of immobilization stress on lipid profile. Indian Journal of Physiology and Allied Sciences. 51: 138-143.

27 Sun J.S., Lu F.J., Huang W.C., Hou S.M., Tsuang Y.H. \& Hang Y.S. 1999. Antioxidant status following acute ischemic limb injury: a rabbit model. Free Radical Research. 31: 9-21.

28 Swaner J.C. \& Connor W.E. 1975. Hypercholesterolemia of total starvation: its mechanism via tissue mobilization of cholesterol. American Journal of Physiology. 229: 365-369.

29 Yagi K. 1987. Lipid Peroxides and human diseases. Chemistry and Physics of Lipids. 45: 337-351.

30 Yu B.P. 1994. Cellular defenses against damage from reactive oxygen species. Physiological Reviews. 74: 139-162. 